\title{
A Process for the Critical Analysis of Instructional Theory
}

\author{
Jay A. Bostwick \\ $B Y U$ \\ Isaac W. Calvert \\ $B Y U$ \\ J. Francis \\ BYU \\ Melissa Hawkley \\ $B Y U$ \\ Curtis Henrie \\ $B Y U$
}

See next page for additional authors

Follow this and additional works at: https://scholarsarchive.byu.edu/facpub

Part of the Educational Methods Commons

\section{Original Publication Citation}

Educational Technology Research and Development, 62(5),511-582.

\section{BYU ScholarsArchive Citation}

Bostwick, Jay A.; Calvert, Isaac W.; Francis, J.; Hawkley, Melissa; Henrie, Curtis; Hyatt, Fred R.; Juncker, Janele; and Gibbons, Andrew S. III, "A Process for the Critical Analysis of Instructional Theory" (2014). Faculty Publications. 2970.

https://scholarsarchive.byu.edu/facpub/2970

This Peer-Reviewed Article is brought to you for free and open access by BYU ScholarsArchive. It has been accepted for inclusion in Faculty Publications by an authorized administrator of BYU ScholarsArchive. For more information, please contact ellen_amatangelo@byu.edu. 


\section{Authors}

Jay A. Bostwick, Isaac W. Calvert, J. Francis, Melissa Hawkley, Curtis Henrie, Fred R. Hyatt, Janele Juncker, and Andrew S. Gibbons III

This peer-reviewed article is available at BYU ScholarsArchive: https://scholarsarchive.byu.edu/facpub/2970 
Title: A Process for the Critical Analysis of Instructional Theory

Authors: Jay A. Bostwick, Isaac Wade Calvert, Jenifer Francis, Melissa Hawkley, Curtis R. Henrie, Frederick R. Hyatt, Janeel Juncker, Andrew S. Gibbons

Affiliation: Brigham Young University, Provo, Utah

Author Biographies: Jay A. Bostwick is a master's student in Instructional Psychology \& Technology interested in facilitating intercultural learning. Isaac Wade Calvert is a PhD student in Instructional Psychology \& Technology studying apprenticeship, creativity and human teaching. Jenifer Francis is in the Instructional Psychology \& Technology master's program, studying instructional design to improve motivation and communication. Melissa Hawkley is a doctoral student in Instructional Psychology \& Technology whose research interests include agency theory and learning, critical flexibility, and developmental evaluation. Curtis R. Henrie is a doctoral student researcher in Instructional Psychology \& Technology studying blended learning and student engagement. Frederick R. Hyatt is a master's student in Instructional Psychology and Technology studying Human Computer Interaction and Performance Improvement. Janeel Juncker is a master's student in Instructional Psychology \& Technology studying the meaning and dynamics of learning and teaching in cultures of creativity and innovation. Andrew S. Gibbons is Chair of the Instructional Psychology and Technology department at Brigham Young University.

Abstract: Some have argued for a common language in the field of instructional design in an effort to reduce misunderstandings and simplify a multitude of synonymous terms and concepts. Others feel that this goal is undesirable in that it precludes development and flexibility. In this article we propose an ontology-building process as a way for readers to compare and analyze terms and concepts across theories. This process entails the development of categories that emerge from the literature, and the comparison of theories across categories. Such a process can reveal broader concepts that exist beyond specific theoretical terminology, differences in meanings behind common terms used by theorists, a greater understanding of the theorists' intent, and discontinuities and gaps within the theoretical literature.

Keywords: instructional theories, analyze, compare, ontology, terminology, interpret 
A Process for the Critical Analysis of Instructional Theory

\section{Introduction}

Instructional designers are no strangers to the difficulties of making sense of a prolific body of theoretical writing. This paper represents an effort to address this potential confusion among those attempting to understand, use and compare instructional theories. To solve this dilemma, Reigeluth (1983, 1999a) and Reigeluth and Carr-Chellman (2009a) tried to articulate common structures among theories and provoke discussion between various theoretical circles within instructional design. In the latter part of their project, they attempted "some early steps in building a common knowledge base about instruction with a common use of terms" (Reigeluth \& Carr-Chellman, 2009b, p. xi). They believed this step was necessary for clear scholarly discussion as well as for seeking commonalities among theories and a framework for their interpretation.

However, some of the participants in Reigeluth's Delphi study were resistant to this attempt to unify the field around common terms, believing that "fuzziness" and "flexibility" are useful to a growing and complex knowledge base (Reigeluth \& Carr-Chellman, 2009c, pp. 1718). Standardization, for them, runs the risk of constraining beneficially divergent ways of thinking about the underlying issues of instructional theory. Yanchar and Gabbitas (2011) also assert that "orthodoxy operat[es] under a single perspective and, ipso facto, lacks genuine openness to itself and alternatives." Thus, a homogeneous theoretical framework proposed too soon could preclude an analytic sensitivity that openness affords to the critical reader analyzing current instructional theory.

Conversely, there is a concern about the tendency for eclecticism in collecting ideas uncritically from different theoretical bases. We do not suggest theoretical eclecticism, or 
"borrowing from a variety of conceptual resources" with little or no regard for their corresponding theoretical or philosophical assumptions and implications (Yanchar \& Gabbitas, 2011). However, we do argue against prematurely constraining categories of theoretical discourse. Instead, we propose a process of critical thinking about instructional theory whereby discerning readers can gain increased understanding through comparison-enabling analysis of their own. This process "emphasizes an awareness of background understanding but construes it as capable of being explicated, critically examined, adjusted in specific contexts, and refined or developed over time to increasingly flexible and effective design practices" (Yanchar \& Gabbitas, 2011). This method is embodied in ontology-building, which we describe below.

\section{Background}

\section{Clarifying the Use of the Term Instructional Theory}

In offering a process for the critical analysis of instructional theory, it is necessary to clarify the term theory, as it is used in this paper in multiple senses. We distinguish between two main categories of theory: scientific and technological. Scientific theory is concerned with the forces that drive both natural and human-made phenomena. Technological theory is concerned with synthesis of designs and how natural forces can be manipulated and applied for the accomplishment of human purposes. Simon (1999) makes this distinction:

As soon as we introduce 'synthesis'...we enter the realm of engineering. For 'synthetic' is often used in the broader sense of 'designed' or 'composed'. We speak of engineering as concerned with 'synthesis' while science is concerned with 'analysis' (p. 7).

According to Vincenti (1990): "Technology appears, not as derivative from science, but as an autonomous body of knowledge, identifiably different from scientific knowledge with which it interacts" (pp. 3-4). Scientific research controls variables in a setting in order to observe and 
make inferences about the relationships between them. Thus, its goal is to produce explanations and answers the question of "Why?" Klir (1969) describes how designers study systems, as do scientists, but instead of waiting to see what the outcome will be, the designer arranges variables in order to reach a particular outcome. For the designer the outcome is not the mystery: It is the arrangement of variables necessary to produce an outcome that is in question.

Within the category of technological theory we describe two kinds of theory relevant to those involved with instructional design: design theory and domain theory. Design theory pertains to how designs are made. Designers in any design field, including instructional design, are interested in and contribute to design theory.

In contrast, domain theory pertains to a particular domain or field of design. Instructional theory is one species of domain theory, in that it concerns itself with principles of effective designs within the domain of instruction. A computer designer can employ design theory, but would not find instructional theory useful in creating computer designs. Distinguishing types of domain theory and considering instructional theory as a type of domain theory allows instructional designers to explore the properties of instructional theory, which is the exclusive focus of this paper (Gibbons \& Rogers, 2009).

\section{An Ontological Approach to the Analysis of Instructional Theory}

We propose ontology-building as a means to analyze and compare instructional theory. We distinguish our use of the term "ontology" from its philosophical definition: the study of the nature of being. Rather, we borrow the computer science and information science concept of ontology: "A specification of a representational vocabulary for a shared domain of discourse definitions of classes, relations, functions, and other objects" (Gruber, 1993; see also Jepsen, 2009). Ontologies allow systems, such as artificial intelligence agents, to interpret and act on 
inputs from humans and other systems, and to provide outputs that can be understood and used by other humans or systems. It is a means to share knowledge without requiring agents to contain the same "data structures" (Gruber, 1993).

One example of a system that uses ontologies is Google Search. Google Search uses a system of algorithms, search histories, and a complex ontology, among other resources, to interpret search queries and provide the most relevant response as a list of search results or information summaries (see "How search works" and "The Knowledge Graph"). Users do not have to use a precise term to find relevant results. For instance, one search term may be more popular among users, but Google Search, using an ontology, is able to link less common, synonymous words people might use in a search query to locate results relevant to the query. The results retrieved may not even use the synonymous word within the online resource, but because information has been defined and relationships have been made in an ontology, Google Search is able to make useful interpretations of complex language use.

Over the past two decades, various methods for ontology-building have developed (Corcho, Fernández-López \& Gómez-Pérez, 2003). Many approaches to developing an ontology involve iteration: continually reviewing, defining and redefining, and establishing relationships between information within a domain (see Noy \& McGuiness, 2001). Ontological engineers recognize, for example, that "there is no one correct way to model a domain - there are always viable alternatives" (Noy \& McGuinness, 2001, p. 4). Jepsen (2009) distinguishes between two major types of ontology: transcendent and immanent. Transcendent ontologies are "authoritative and defined externally," resulting in a closed, rigid framework (p. 24). In contrast, immanent ontologies are characterized as open and flexible, allowing for expansion and revision as knowledge domains change or become better defined by its users. 
We believe that ontology-building as performed by the computer science field can be repurposed into a powerful tool to examine the nature of instructional theory in general and to understand and identify commonalities and differences among specific instructional theories. Reigeluth suggests this by introducing each chapter of Volumes II and III of his InstructionalDesign Theories and Models (Reigeluth, 1999a; Reigeluth \& Carr-Chellman, 2009a) with an ontological summary in which common categories are specified as a basis for describing and comparing theories. For example, the foreword to each chapter uses categories such as goals, preconditions, values and methods to summarize each theory, in the interest of "building a common knowledge base" (Reigeluth, 2009a). An ontology-building process affords a reader of instructional theory with the capability to not only critically analyze the theory, but also to compare the underlying concerns addressed by different theorists at a much greater level of detail that goes beyond mere terminology.

We do not hold to the idea that a common set of categories should currently be specified to facilitate the analysis of all instructional theories, present and future. This approach is akin to transcendent ontologies, which represent a closed and unchanging knowledge base. Instructional theory is a relatively new and expanding knowledge base, with more development yet to come. Reigeluth's framework presents a good starting point for the discussion of the nature of instructional theory; however, it should not be the only approach. We found that analyzing individual theorists and trying to discern their categories not only allowed us to compare the common categories used across theorists as Reigeluth hoped to do, but also suggested new categories that may be idiosyncratic to the theorist or discovered by the reader. Utilizing an imminent ontology-building process, consumers of instructional theory can become aware of new categories and relationships of concepts in instructional theory and expand their 
understanding of theoretical issues. Moreover, as theories are read more critically in this way, understanding and discussion of their underlying ideas can become more open-ended and capable of growth rather than taxonomical.

\section{Research Method}

We began a critical analysis of theory as part of a special topics graduate-level course on instructional theory, using Volume II of Reigeluth's Instructional Design Theories and Models: A New Paradigm of Instructional Theory (1999) as a literature base. Rather than trying to memorize the precepts of the individual theories, we sought to understand the nature of instructional theory. After reviewing the theories in Volume II, we selected a few to examine in greater depth, critically reviewing their major characteristics, assumptions and assertions (Yanchar, Slife, \& Warne, 2008). Specifically, we investigated "Learning by Doing” (Schank, Bermn, \& Macpherson, 1999), “Toward the Development of Flexibly Adaptive Instructional Designs” (Schwartz, Lin, Brophy, \& Bransford, 1999), “Designing Constructivist Learning Environments" (Jonassen, 1999), and "The Elaboration Theory: Guidance for Scope and Sequence Decisions" (Reigeluth, 1999c). We chose these theories as they are familiar to many in the field, and represent a variety of philosophical perspectives of the nature of instructional theory.

Acting as a research team, we conducted a project using a reflective, discussion-based approach (see Halonen, 1999). In our initial examination of the four theories, we found ourselves loosely defining the terms used by the theorists and paraphrasing their messages in our own words. As we tried to make a comparison between theories, however, we realized that we had, in many cases, misapprehended the theorists' meanings by imposing our own assumptions 
upon the theorists' words. To remedy this, we reread each of the theorists more critically, this time trying to understand the conceptual meanings behind their specific terminologies.

For example, in reading Schank et al., it became clear that they were addressing a construct of what is being designed, which we called designed object, and which Schank et al. named "goal-based scenario". This designed object had many characteristics. For example, we realized that this was something that had to be designed and constructed before instruction took place. It was clear, therefore, that the designer of a goal-based scenario would determine the learning outcome in advance of instruction, and that the learning outcome itself was an important element that had to be designed. Moreover, it was apparent that the designer was the one who would choose the goal and design the resources used by the learner prior to the beginning of instruction. Implicitly we understood that this represented a "package" concept in which the physical embodiment of the designed object corresponded with its conceptual boundary.

In contrast, when reading Jonassen, we understood that he also assumed that there were designed objects, but that Jonassen's environment had conceptual embodiment but not necessarily a physical form, whereas a goal-based scenario might exist as a computer file as well as in concept. Moreover, parts of the design were not completely specified in advance and many could be determined at the time of instruction in negotiation with the learner. According to Jonassen, what was designed was an "environment" which might consist of a problem, a project, its context, its representation and/or a manipulation space. This indicated to us that although both theorists implicitly dealt with the construct which we interpreted as designed object, what this consisted of was different in the minds of the two theorists. We saw that both of them were addressing what appeared to be the same ontological category that we had created — the thing to 
be designed — but that both of them were implicitly introducing new subcategories into the discussion of the nature of the designed object.

Then, when we reread Reigeluth, we noted that what was to be designed was a completely abstract, unembodied designed object which he called the "learning episode." Leaving questions of physical package behind, Reigeluth described invisible characteristics which he called "scope" and "sequence." Reigeluth thus made explicit two categories of designed objects which neither Schank et al. nor Jonassen decided to address. At the same time, Reigeluth did not address the "package" and "environment" issues raised by Schank et al. and Jonassen, respectively, at any level of concreteness. After rereading Reigeluth and noting these new categories, we were then able to return to Schank et al. and Jonassen and "interrogate" them with respect to Reigeluth's "scope" and "sequence" categories.

It was only by realizing that each theorist had a concept of what should be designed and then creating the ontological category, designed object, that we were able to make an analytic comparison of their different terminologies. Without this identification of an ontological category, there was no reason to believe that "goal-based scenarios", "environments", and "learning episodes" had anything in common. We found that by building the category, we had created an analytical tool that not only enabled comparisons between theories, but also helped us identify what elements of the designed object each theorist chose to address or ignore. Instead of being reduced to memorizing the theorists' terminology, this new tool afforded us a finer-grained analysis and comparison of the theories.

The value of this category became even more apparent as we reread Schwartz et al. (Star Legacy) and realized that in our initial readings we had assumed that what they were describing was simply a cycle of instruction. What we had missed was that the designed object was not just 
designed by the instructor, but also the learner and other stakeholders as instruction proceeded. It became apparent that Schwartz et al. were not talking about designing objects in the more traditional context that the other theorists had been describing: how one ought to use the design process to instruct. Instead, instruction and design occur at the same time. So once again, the ontological category designed object provided a Rosetta stone for interpreting a theory without the baggage of our own prior and hasty assumptions. It became apparent that Schwartz et al. were not talking about just the design process or just designed objects. They were talking about the intersection between instruction and design. For us, this was a paradigm breaker-we realized that you don't have to design something in advance; design and instruction can occur contemporaneously.

At this point we tried to introspect about the process that had enabled us to make these more detailed comparisons between theories. We had not set out with the idea of ontologybuilding, but rather with the goal of understanding how to compare theories. When we realized that we had been doing ontology-building we initiated a study into that process to determine whether there was strong precedent that might lead us to a generalizable methodology for theory analysis. We discovered that there was indeed sufficient precedent and that we should attempt to formalize the process which we are describing in this paper.

Through additional literature study, we also became aware of a process by which theoretical constructs become diluted and distorted over time as they are applied more widely outside the close control of the theorist. In particular, we studied McDonald's (2006) analysis of “Technology I, II, and III", proposed in the 1960s to describe why and how theories appear to lose their effectiveness in the hands of the general designer. McDonald used case studies of 
programed instruction and problem-based learning to show how applications of theory run afoul of the originator's purpose and lose their clarity over time in the hands of numerous designers.

At the beginning of our inquiry into the nature of instructional theory, we did not realize where we would end up, and even now we do not claim to have arrived at an authoritative ontology that represents a comprehensive key to understanding instructional theory. On the contrary, we feel that we stumbled across a conceptual tool that all readers may use to analyze instructional theories by reading "through" the specific terms used by a theorist and seeing "into" the ontological categories suggested by the terms.

We realized through our class discussions that it was difficult for class members to come to a common understanding of any particular category that was under discussion and that most often, during the process of discussion, insights to new ontological categories multiplied, creating new understandings that none of us had anticipated. Our own ontological categories grew in step with our growing understanding of each theory. The process was more painful than any of us had expected. At times, class members were dismayed at the complexity introduced by continually subdividing ontological categories. It appeared that we were headed into a reductionist abyss, and yet the reward for patience with the process was not a reification of specific categories as much as an initiation into a process that enabled the discussion and analysis of theories old, new, and yet to come.

\section{Findings}

In this section we present five insights that arose from the application of our ontologybuilding process:

1. Concepts exist in theoretical writing that theorists do not address directly. 
2. These tacit concepts, which supply the ontological categories, enable a more detailed comparison of theories beyond specific terminologies.

3. Divergences between theories can be concealed behind common terms used by different theorists.

4. A false sense of understanding often arises from a cursory, uncritical reading of the theories.

5. Discontinuities and gaps are revealed within the theoretical literature when the tacit concepts are elicited.

First, we found that each instructional theory used its own distinctive terminologies, yet each addressed tacit questions, problems, and concerns shared by other theorists that were not directly addressed, but rather assumed, by the theorist. As described earlier, we observed that Schank et al.'s goal-based scenarios, Jonassen's constructivist learning environments, Reigeluth's learning episodes, and Schwartz et al.'s Star Legacy all addressed the broader concept we termed designed objects, even though their different terminologies initially suggested to us otherwise. Kahneman (2011) identified a common rational fallacy that he labels "What You See Is All There Is" (WYSIATI). WYSIATI is the tendency to focus on the information that is actually given, the "known knowns," while overlooking that which is missing, the "known unknowns" or the "unknown unknowns." In our case, the "unknown" was the idea of designed object, or the thing to be designed. Sticking strictly to the theorists' terms can forestall the comparing of theories that reveals commonalities. However, by abstracting common principles and creating ontological categories that can circumscribe varying ideas on a common theme, we can more easily enable comparison and analysis. 
Second, tacit concepts created ontological categories that enabled comparison beyond the terms actually give by the theorist. We discovered this as we continued to take ontological categories emerging from the reading and use them to analyze additional theories. One of the ontological categories we abstracted from our reading was mechanisms to motivate learners. Without explicitly addressing motivation as a topic of their theory, several of the theorists identified aspects of theory that enhanced student motivation. Keeping notes on these aspects allowed us to compare and examine what instructional methods have been identified to influence student motivation (see Table 1).

Table 1

Example of Instructional Theories Comparison

\begin{tabular}{|c|c|c|c|}
\hline $\begin{array}{c}\text { Ontological } \\
\text { Category }\end{array}$ & $\begin{array}{c}\text { Schank et al./ } \\
\text { Goal-based Scenarios }\end{array}$ & $\begin{array}{c}\text { Jonassen/ } \\
\text { Constructivist Learning } \\
\text { Environments }\end{array}$ & $\begin{array}{l}\text { Reigeluth/ } \\
\text { Elaboration Theory }\end{array}$ \\
\hline $\begin{array}{l}\text { Mechanisms } \\
\text { for } \\
\text { motivating } \\
\text { learners }\end{array}$ & $\begin{array}{l}\text { Example: Learners are } \\
\text { motivated by providing } \\
\text { interesting goals. } \\
\text { "You should choose a } \\
\text { goal that you know the } \\
\text { student will relate to } \\
\text { either in that it is } \\
\text { something they would } \\
\text { already like to do or } \\
\text { because it is something } \\
\text { that she would think was } \\
\text { fun to do upon } \\
\text { suggestion" (p. 174). }\end{array}$ & $\begin{array}{l}\text { Example: Learners are } \\
\text { motivated by } \\
\text { encountering ill-structured } \\
\text { problems. } \\
\text { "It must be interesting, } \\
\text { appealing and } \\
\text { engaging...ill-defined or } \\
\text { ill-structured, so that some } \\
\text { aspects of the problem are } \\
\text { emergent and definable by } \\
\text { the learners. It must } \\
\text { perturb the learner" (p. } \\
219,221) \text {. }\end{array}$ & $\begin{array}{l}\text { Example: Learners are } \\
\text { motivated when } \\
\text { instruction sequences } \\
\text { the performance from } \\
\text { basic to more complex. } \\
\text { "The elaboration theory } \\
\text { was developed to } \\
\text { provide a holistic } \\
\text { approach to sequencing } \\
\text { that also makes the } \\
\text { learning process more } \\
\text { meaningful and } \\
\text { motivational to } \\
\text { learners" (pp. 427-428). }\end{array}$ \\
\hline
\end{tabular}

One by one, as we identified various ontological categories, we could target specific aspects of a theory that could be compared and analyzed across other theories. This approach allowed us to compare the underlying concepts using a common denominator. 
Third, we found that, while theorists may use different terms for shared ideas and assumptions, they can also use the same terms in a way that conceals theoretical divergences. It is common for readers to interpret a term, like knowledge, the same across theories. Examining our selected theories ontologically, however, revealed to us the divergent assumptions lurking beneath this common term. Schank et al. define knowledge, not just as facts, but as the performance of "skills in a functional manner to achieve...goals" (p. 167). Jonassen, on the other hand, asserts that knowledge is that which is "socially constructed by learners based on their interpretations" (p. 217). Instructional design theory is full of common terms and phrases such as learning, lesson, exercise, problem, etc. As with the term knowledge, the habit of interpreting these terms according to one's own understanding, rather than investigating the specific meaning that a theorist intends, can lead to theoretical eclecticism and to significant misunderstandings and misapprehensions of similarities and differences between theories.

Fourth, because the meanings behind the terms were not apparent at first, our cursory reading led us to a false sense of understanding. We experienced the same problem that occurred with the interpretation of Barrows's "problem-based learning" (PBL) theory. Once PBL demonstrated its effectiveness, it became widely adopted. Later, however, Barrows (1998) noted the transformation of PBL in the hands of other designers that rendered their instructional designs significantly different in principle from what he originally proposed:

Few teachers may actually appreciate the wide differences possible in educational methods that are referred to as PBL. The term PBL is so non-specific that it may be hard to conceptualize what it could be in it's [sic] fullest as an educational method. This wide variation impedes communication. Without observation, the exact nature of the learning methods are $[s i c]$ unknown. The variation also makes any meaningful assessment of PBL 
a nightmare - a problem confronted by two comprehensive meta-evaluations of PBL ( $\mathrm{p}$. 630).

Because of misapprehension and misuse of the theory, Barrows proposed the term "authentic PBL" as a way to distinguish his theory from other versions that had been developed. We recognized a tendency on our own part to misapprehend a theorist's intent as we initially studied instructional theories independently of one another. It was when we began to recognize the underlying ontological categories as they emerged from the reading that we examined the theories more carefully, finding the meanings and assumptions behind the theorists' terms that enabled the discovery of meaningful differences and similarities across theories.

Fifth, this ontology-building process revealed discontinuities and conversational gaps in the theoretical literature. As indicated previously, though Schank et al., Jonassen, and Reigeluth shared in common the ontological category designed object, we also detected ontological categories particular to their theories. Knowing this, we were able to reexamine each of the theories, seeking the missing ontological categories and speculate whether the theorist had omitted them on purpose or through oversight.

For example, after carefully reading Schwartz et al., we discovered a concept that the theorist called "flexibly adaptive instructional design," which, according to the authors, is "a collaborative and emerging process involving 'initial designers,' teachers, community members, and even students themselves" (p. 189). Noticing this created for us an ontological category we hadn't previously considered that we called who designs the instruction, which led in turn to several additional categories that are implied but not specified (e.g. the joint role of the designer and the teacher, the joint role of the teacher and the student, the joint role of the designer and the student). This enabled us to return to other theories to examine not just their details, but also 
the scope of their application. Having found this, which almost slipped past us, the natural question was, "What other issues could be considered by theorists legitimately that have up to this point been ignored, and what future theories may be put forth to address these gaps?"

\section{Conclusion}

In this paper, we have proposed critically analyzing instructional theory through a process of ontology-building. This iterative process involves reading instructional theory, developing ontological categories of concepts and characteristics found within and implied by the theorists' terms, analyzing other instructional theory directed by those categories, and further refining categories as new concepts and characteristics are realized. We found that this method enables consumers of instructional theory to compare theories more accurately and in greater detail. This process also reveals broader concepts that exist beyond specific theoretical terminology, differences in meanings behind common terms used by theorists, a greater understanding of the theorists' intent, and discontinuities and gaps within the theoretical literature.

Ontology-building involves not only the identification of objects and constructs of a knowledge domain, but the relationships between them as well. Our own process focused on the creation of categories. Additional work could be done in discussing relationships between ontological categories within instructional theory.

The focus of this article has been on the personal development of ontologies to assist readers in analyzing and comparing instructional theories. We have shared elements of our ontology to illustrate its development and use, but resist publishing a developed ontology to be used by other readers. As we each engaged in this ontology-development process singly as authors, we found some similarities between our ontologies but also many differences. It is the 
process of making an ontology that is most valuable, not the ontology itself. Further, we believe differences in ontologies better allow for open interpretation and dialogue of the nature of instructional theory.

Reigeluth suggested the value of examining theories in terms of their common categories. Our work builds on Reigeluth's notion that theories can be better understood by examining their shared concepts; however, we recommend using an immanent ontology-building process to enhance one's critical analysis and comparison of instructional theories in preference to the establishment of a transcendent ontology. We believe that the tool of immanent ontologybuilding provides not only a touchstone for the interpretation of existing instructional theories, but also reveals potential topics for further theoretical development. 


\section{References}

Barrows, H. S. (1998). The essentials of problem-based learning. Journal of Dental Education, 62(9), 630-633.

Corcho, O., Fernández-López, M. \& Gómez-Pérez, A. (2003). Methodologies, tools and languages for building ontologies. Where is their meeting point? Data Knowledge and Management 46, 41-64. doi:10.1016/S0169-023X(02)00195-7

Gibbons, A. S., \& Rogers, P. C. (2009). The architecture of instructional theory. In C. M. Reigeluth \& A. A. Carr-Chellman (Eds.), Instructional-Design Theories and Models, (Vol. 3, pp. 305-326). Mahwah, NJ: Lawrence Earlbaum Associates.

Gruber, T. R. (1993). A Translation Approach to Portable Ontology Specifications. Knowledge Acquisition, 5(2), 199-220.

Halonen, J. S. (1999). On critical thinking. In B. Perlman, L. I. McCann, \& S. H. McFadden (Eds.), Lessons learned: Practical advice for the teaching of psychology (pp. 121-125). Washington D.C.: American Psychological Society.

How search works. (n.d.). Retrieved from http://www.google.com/insidesearch/howsearchworks/thestory/

Jepsen, T. C. (2009). Just what is an ontology, anyway? IT Professional, September/October, $22-27$

Jonassen (2009). Designing constructivist learning environments. In C. M. Reigeluth (Ed.), Instructional-design theories and models: A new paradigm of instructional theory (Vol. 2, pp. 215-240). Mahwah, NJ: Lawrence Erlbaum Associates.

Kahneman, D. (2011). Thinking fast and slow. New York, NY: Farrar, Straus and Giroux.

Klir, G. J. (1969). An approach to general systems theory. New York, NY: Van Nostrand Reinhold Company. 
The Knowledge Graph (n.d.). Retrieved from http://www.google.com/insidesearch/features/search/knowledge.html

McDonald, J. K. (2006). Technology I, II, and III: Criteria for understanding and improving the practice of instructional technology. (Doctoral Dissertation). Retrieved from ProQuest.

Noy, N. F., \& McGuinness, D. L. (2001, March). Ontology development 101: A guide to creating your first ontology. Stanford Knowledge Systems Laboratory Technical Report. Retrieved from http://www.ksl.stanford.edu/people/dlm/papers/ontology-tutorial-noymcguinness.pdf

Reigeluth, C. M. (Ed.). (1983). Instructional-design theories and models: An overview of their current status (Vol. 1). Hillsdale, NJ: Lawrence Erlbaum Associates.

Reigeluth, C. M. (Ed.). (1999a). Instructional-design theories and models: A new paradigm of instructional theory (Vol. 2). Mahwah, NJ: Lawrence Erlbaum Associates.

Reigeluth, C. M. (1999b). What is instructional-design theory and how is it changing? In C. M. Reigeluth (Ed.) Instructional-design theories and models: A new paradigm of instructional theory, (Vol. 2, pp. 5-29). Mahwah, NJ: Lawrence Erlbaum Associates.

Reigeluth, C. M. (1999c). The elaboration theory: Guide for scope and sequence decisions. In C. M. Reigeluth (Ed.) Instructional-design theories and models: A new paradigm of instructional theory, (Vol. 2, pp. 425-454). Mahwah, NJ: Lawrence Erlbaum Associates.

Reigeluth, C. M., \& Carr-Chellman, A. A. (Eds.). (2009a). Instructional-Design Theories and Models, (Vol. 3). Mahwah, NJ: Lawrence Earlbaum Associates.

Reigeluth, C. M., \& Carr-Chellman, A. A. (2009b). Preface. In C. M. Reigeluth, \& A. A. CarrChellman, (Eds.). Instructional-Design Theories and Models, (Vol. 3, pp. xi-xii). Mahwah, NJ: Lawrence Earlbaum Associates. 
Reigeluth, C. M., \& Carr-Chellman, A. A. (2009c). Understanding instructional theory. In C. M. Reigeluth, \& A. A. Carr-Chellman, (Eds.). Instructional-Design Theories and Models, (Vol. 3, pp3-26). Mahwah, NJ: Lawrence Earlbaum Associates.

Schank, R. C., Berman, T. R., \& Macpherson, K. A. (1999) Learning by doing. In C. M. Reigeluth (Ed.). Instructional-design theories and models: A new paradigm of instructional theory (Vol. 2, pp. 161-182). Mahwah, NJ: Lawrence Erlbaum Associates.

Schwartz, D., Lin, X., Brophy, S., \& Bransford, J. D. (1999). Toward the development of flexibly adaptive instructional designs. In C. M. Reigeluth (Ed.). Instructional-design theories and models: A new paradigm of instructional theory (Vol. 2, pp. 183-214). Mahwah, NJ: Lawrence Erlbaum Associates.

Simon, H. A. (1999). The sciences of the artificial (3rd ed.). Cambridge, MA: MIT Press.

Vincenti, W. G. (1990). What engineers know and how they know it: Analytical studies from aeronautical history. Baltimore, MD: Johns Hopkins University Press.

Yanchar, S. C., \& Gabbitas, B. W. (2011). Between eclecticism and orthodoxy in instructional design. Educational Technology Research and Development, 59, 383-398.

Yanchar, S. C., Slife, B. D., \& Warne, R. (2008). Critical thinking as disciplinary practice. Review of General Psychology 12(3), 265-281. doi:10.1037/1089-2680.12.3.265 